\section{Public Health} Genomics
Public Health Genomics 2015;18:237-241

DOI: $10.1159 / 000431020$
Received: January 15, 2015

Accepted: April 29, 2015

Published online: June 4, 2015

\title{
Perspectives in Genetics and Sickle Cell Disease Prevention in Africa: Beyond the Preliminary Data from Cameroon
}

\author{
Ambroise Wonkam $^{a}$ Valentina Josiane Ngo Bitoungui ${ }^{b}$ Jeanne Ngogang ${ }^{b}$ \\ a Division of Human Genetics, Faculty of Health Sciences, University of Cape Town, Cape Town, Republic of South \\ Africa; ${ }^{b}$ Department of Microbiology, Parasitology and Haematology, Faculty of Medicine and Biomedical Sciences, \\ University of Yaoundé 1, Yaoundé, Cameroon
}

\section{Key Words}

Sickle cell disease - Genetics · Prevention - Cameroon .

Sub-Saharan Africa

\begin{abstract}
Management of sickle cell disease (SCD) in Africa needs to be accompanied by various preventive strategies, including early detection via prenatal genetic diagnosis (PND). Contrary to Cameroonian doctors who considered termination of an affected pregnancy (TAP) for SCD in $36.1 \%$, the majority of parents $(62.5 \%)$ with affected children accepted TAP in principle. In practice, most women opted for TAP $(90 \%)$, justified by a huge psycho-social burden. The ethical and legal challenges of PND prompted the need to explore the use of genetics for secondary prevention of SCD. In 610 Cameroonian SCD patients, the genomic variations in two principal foetal haemoglobin-promoting loci were significantly associated with foetal haemoglobin levels. In addition, the coinheritance of a 3.7-kb a-globin gene deletion and SCD was associated with a late disease onset and possibly improved survival: there was a much higher allele frequency of the 3.7kb a-globin gene deletion in SCD patients $(\sim 40 \%)$ than in haemoglobin AA controls ( 10\%). The data indicate the urgent need to develop and implement policy actions in subSaharan Africa on at least four levels: (1) the implementation
\end{abstract}

of SCD screening practices and early neonatal follow-up; (2) the development and incorporating of socio-economic support to alleviate the burden of SCD on affected families; (3) the exploration of the appropriateness of the medical abortion laws for SCD, and (4) the development of national plans for genetic medicine, including research on genomic variants that affect the phenotypes of SCD, in order to potentially use them for anticipatory guidance.

(c) 2015 S. Karger AG, Basel

\section{Introduction}

Cameroon is a country of 20 million inhabitants, with a carrier frequency of sickle cell disease (SCD) ranging from 8 to $34 \%$ [1]. Despite the exceptional severity illustrated by a high prevalence of stroke (6.7\%) in SCD patients [2], there are no specialized centres for lifelong medical care in Cameroon. Therefore, management needs to be accompanied by various preventive strategies. Prevention also extends to early detection with the aim to identify SCD in the foetus, provide reproductive options and options for treatment and prognosis.

Wonkam and Ngo Bitoungui are members of the H3Africa Consortium.

\section{KARGER 125}

(c) 2015 S. Karger AG, Base

$1662-4246 / 15 / 0184-0237 \$ 39.50 / 0$

E-Mail karger@karger.com

www.karger.com/phg
Assoc. Prof. Ambroise Wonkam

Division of Human Genetics, Faculty of Health Sciences

University of Cape Town

Anzio Road, Observatory 7925, Cape Town (Republic of South Africa)

E-Mail ambroise.wonkam @ uct.ac.za 


\section{Ethical Challenges of Prenatal Genetic Diagnosis for SCD}

\section{Acceptance of Prenatal Genetic Diagnosis for SCD}

We reported that in Cameroon, the majority of preclinical students, clinical medical students and doctors described the principle of prenatal genetic diagnosis (PND) for SCD as acceptable $(77.6,64.8$ and $78.7 \%$, respectively), but in the three groups, the acceptance of termination of an affected pregnancy (TAP) for SCD was lower (22.4, 10.8 and $36.1 \%$, respectively) [3].

The views of doctors could be influenced by prospects in treatments of SCD such as hydroxyurea [4] or by a possible cure with stem cell (cord blood or bone marrow) transplantation [5], even though these options are largely not available to Cameroonian SCD patients [6]. However, the majority of parents that had children affected by SCD accepted, in principle, PND (89.8\%) and TAP (62.5\%) for SCD [7], with the acceptance for TAP increasing with unemployment and the total number of children in the family. The chronicity of SCD could impair the quality of life of caregivers. Using Likert-type statements in a survey instrument, including 38-item stress factors, we evaluated the general perceptions of stress and five main specific stressors in parents: disease factors (clinical severity), hospital factors, financial factors, family factors (life/dynamic) and SCD-child factors (perceived quality of life) [6]. There were four response options with increasing severity $(0,1,2$ and 3$)$; ' 2 ' scored for 'moderate difficulty' and ' 3 ' for 'severe difficulty'. The majority of participants (88.3\%) experienced moderate to severe difficulty in coping with SCD. The median score of SCD clinical severity was the major factor that undermined the coping ability of parents (2.2); vaso-occlusive painful events ( $>3$ per year) were the disease-related stressors that most impacted their coping ability [6]. Similar data were also reported in Nigeria, where a sample of doctors and a group of health professionals would accept TAP for SCD in 21.4\% [8] and 33\% [9], respectively, while $92 \%$ of the SCD Nigerian mothers who were heterozygous carriers favoured PND for SCD, and $63 \%$ would opt for TAP [10]. Like in Cameroon, $\mathrm{Ni}$ gerian parents with SCD-affected children disclosed a high burden of SCD on their families [11]. Suprisingly, adult patients living with SCD in Cameroon were supportive of PND (89.2\%), and a remarkably high number found TAP for SCD acceptable (40.9\%) [12]. This was based on their own relatively poor quality of life and also on their interest in the future well-being of affected children $[12,13]$. Similarly, $85 \%$ of the female SCD patients in Nigeria accepted PND for SCD, and 35\% indicated they would opt for TAP [10]. It is possible that some SCD patients in Cameroon and Nigeria had such a poor quality of life that they did not find their own lives worth living. Therefore, they did not want other children to make the same experience; an alarming finding that requires urgent attention of policy makers [12]. PND for SCD was introduced in Cameroon in 2007, following a serious debate on the value judgement of what is considered a life worth living, the possibility of stepping down the slippery slope towards eugenics and the legality of TAP [14].

\section{Attitude about TAP for SCD}

In actual practice, most women opted for TAP (90\%). Among them, 93.9\% had either an SCD-affected child or sibling $[15,16]$. Similarly, in Nigeria, following the introduction of PND for SCD, up to $96 \%$ of the women with SCD-affected foetuses terminated the pregnancies. Among them, 51\% previously had children with SCD [17]. In Cameroon, the possibility of having a child with SCD was not realized before marriage by $85.7 \%$. Up to $21.4 \%$ of the women admitted to have voluntarily terminated at least one pregnancy in the past, for fear of having an SCD-affected child [16]. This was a surprising revelation, since under Cameroonian law, voluntary abortion is a criminal offence, whilst medical abortion is permitted '... if it is done by an authorised professional and justified by the need to save the mother from grave health jeopardy' (Act 339; exception 1; The Cameroon Penal Code). The studies signal potential value-based conflicts among Cameroonian students, doctors, parents and patients regarding the principle and practice of TAP for SCD. The conflicts could be partly embedded in the differentially perceived severity and curability of SCD, the restrictive abortion laws, cultural values and beliefs, the major burden of SCD on patients and families, as well as the environment compounded by socio-economic difficulties and a dysfunctional health system $[6,13]$. We also reported on the increasing burden of SCD and the introduction of PND for SCD in clinical practice in Cape Town, South Africa [18]. In practice, although the majority of parents would like to take the option of PND for SCD, they mostly disagreed with the idea of TAP for SCD [19]. Contrary to the Central Hospital in Yaoundé, Cameroon, at the Red Cross War Memorial Hospital in Cape Town, there is a provision of a specialized free-of-charge comprehensive clinic, with all possible available care and therapeutic options for SCD. It is therefore possible that a more favourable social environment and hospital services could improve the ability of parents and patients to cope with SCD and lead to a lower desirability of TAP for SCD in 
Cameroon. This hypothesis will require further investigations in order to frame appropriate policies that allow parents to opt for reproductive options that do not conflict with their societal ethics [19]. The ethical and legal challenges around the practice of PND prompted the need to develop and extend our studies to the potential use of genetics for secondary prevention of SCD.

\section{Genomics and Secondary Prevention of SCD: Preliminary Data and Perspectives}

\section{Genomics of Foetal Haemoglobin}

Despite SCD being a single-gene disorder, foetal haemoglobin $(\mathrm{HbF})$ is the most important disease modifier, which is genetically determined by three major loci (BCL11A, HBS1L-MYB and HBB cluster) that are amenable to therapeutic manipulation [20]. Among a group of 610 Cameroonian SCD patients (97\% haemoglobin SS), the two principal known HbF-promoting loci were significantly associated with $\mathrm{HbF}$ in Cameroonian patients [21], as previously reported in African SCD patients from the USA [22], Brazil [22] or Tanzania [23]. In Cameroon, single-nucleotide polymorphisms (SNPs) in BCL11A and $H B S 1 L-M Y B$ loci were associated with about $10 \%$ variation in the HbF level in SCD patients, and especially rs 28384513 (HMIP 1) and rs9494142 (HMIP 2) were associated with hospitalization rates, reflecting their influence on the severity of the disease [21]. In addition, BCL11A rs4671393 was significantly associated with a wide range of haematological indices; rs28384513 (HMIP 1) with WBC counts, rs9399137 (HMIP 2) with Hb levels, and rs9402686 (HMIP 2) and rs9494142 (HMIP 2) were both associated with mean corpuscular volume (MCV) [21]. We also replicated the finding previously reported in African American SCD patients in whom the HBS1L-MYB rs9399137 and BCL11A rs4671393 SNPs in combination affected platelet counts [22]. Equally, the effect of these HbF-promoting loci on the haematological phenotype in SCD was reported in Tanzania [24]. Understanding the effect of haematological, variable-associated variants will require additional data from various SCD populations from Africa.

\section{The Co-Inheritance of $\alpha$-Thalassemia and SCD}

In Cameroon, the co-inheritance of a 3.7-kb a-globin gene deletion and SCD was associated with a late SCD onset and possibly improved patient survival, which could be explained by the much higher allele frequency of the 3.7-kb a-globin gene deletion in SCD patients ( $40 \%)$ than in haemoglobin AA controls $(\sim 10 \%)$ [25]. Co-in-

Genetics and Sickle Cell Disease in

Cameroon heritance of SCD and $\alpha$-thalassemia was associated with a lower consultation rate in Cameroonians $(p=0.038)$, implying a lesser severity of disease that could be attributed to its association with improved haematological indices [26]. In generalised linear regression models adjusted for age, sex and HbF-promoting SNPs, the positive effects of the co-inheritance of $\alpha$-thalassemia on red blood cell count, MCV and lymphocyte count were still observed in Cameroonians [26]. In addition, in African Americans and Tanzanians, the co-inheritance of $\alpha$ thalassemia and SCD was associated with a lower stroke risk $[27,28]$.

\section{Other Selected Genomic Variants Associated with SCD Phenotypes}

Specific phenotypes have been associated with genomic variations in SCD in African Americans. One mutation in GOLGB1 (Y1212C) and another mutation in ENPP1 (K173Q) were confirmed as having significant associations with a decreased risk for stroke [29]. Seven SNPs in the myosin, heavy chain 9, non-muscle (MYH9) gene and one in apolipoprotein L1 (APOL1) have been associated with the risk for focal segmental glomerulosclerosis and end-stage renal disease [30]. A genetic association with elevated tricuspid regurgitation jet velocity and pulmonary hypertension was revealed in five SNPs within GALNT13 and a quantitative trait locus upstream of the adenosine $\mathrm{A} 2 \mathrm{~B}$ receptor gene (ADORA2B) [31]. Heme oxygenase-1 (gene $H M O X 1$; protein $\mathrm{HO}-1$ ) is the inducible enzyme in the catabolism of heme and could attenuate the severity of SCD outcomes ranging from vaso-occlusive to hemolytic crises. A (GT)(n) dinucleotide repeat located in the promoter region of the HMOX1 gene is highly polymorphic, with allele lengths varying from 13 to 45 repeats. Long repeat lengths are associated with decreased activity. In a cohort of 942 children with SCD, children with two shorter alleles ( $4 \%$; $\leq 25$ repeats) had lower rates of hospitalization for acute chest syndrome compared to children with longer allele lengths [32]. All these variants that affect cardiovascular phenotypes and acute chest syndrome deserve to be investigated in SCD patients in Africa to fully appreciate their potential clinical values.

In summary, the preliminary data from Cameroon are the first evidence from the African continent of the clinical effect that is associated with selected HbF-promoting SNPs and the co-inheritance of $\alpha$-thalassemia and SCD. These results could suggest that clinical genotyping of these variants and others may be useful to risk stratify SCD patients and to serve as a guide to adjust therapeutic and follow-up plans. 


\section{Public Health Policy Actions}

The postgenome era promises can offer new insights into the nature of SCD, its prevention and treatment; subSaharan African countries need urgent societal and policy adjustments to such progress [33]. The data indicate the urgent need to develop and implement policy actions in Cameroon on at least five levels [19]: (1) the implementation of the national control program of SCD with screening policies that put emphasis on premarital detection to hopefully reduce the number of cases that will be referred to PND; (2) to implement policies and practices that improve the early detection and care of SCD, e.g., neonatal screening, the use of hydoxyurea and the development of specialized centre care for SCD patients; (3) to frame social policies for birth defects and disabilities incorporating socio-economic supports to alleviate the burden of SCD on affected families; (4) to address the appropriateness of the Cameroonian abortion laws, e.g., the maternal distress due to foetal anomalies like SCD as acceptable justification for medical abortion, and (5) to develop a national plan for genetic medicine, including a specific research program for SCD and the related genetic education for health professionals and the general public.

\section{Conclusion}

The differential acceptability in the principle and practice of TAP for SCD in Cameroon revealed the potential value-based conflicts in various population groups. The molecular data support some perspectives in the clinical genotyping of $\alpha$-globin gene deletion, HbF-promoting genomic variants and others yet to be found that may be useful to risk stratify SCD patients and to serve as a guide for therapeutic and follow-up strategies. The present report summarised a modest body of work from a single African country, which, in addition to other reports, could be of unique value to some developing settings willing to explore the use of genetics in SCD prevention; indeed, PND of haemoglobinopathies represents the point of entry of genetic medicine in many developing countries [34]. Finally, these data were generated in Africa by African scientists; this could contribute to fast-track the most needed regional capacity building in social sciences coupled with genetic research [35] to offer different perspectives to improve the care of SCD patients in Africa.

\section{Acknowledgments}

The molecular experiments of the study were funded by the National Health Laboratory Services, South Africa, and the University Research Committee and Carnegie Research Development grant, University of Cape Town, South Africa. The students' bursaries were provided by the National Research Foundation-DAAD scholarship, South Africa, and the Third World Academy of Sciences. The National Institute of Health (NIH), USA, funded the report and publication of the present work (grant No. 1U01HG007459-01).

\section{Disclosure Statement}

The authors declare that there are no conflicts of interest to disclose.

\section{References}

1 Weatherall DJ, Clegg JB: Inherited haemoglobin disorders: an increasing global health problem. Bull World Health Organ 2001;79: 704-712.

-2 Njamnshi AK, Wonkam A, Djientcheu Vde $\mathrm{P}$, et al: Stroke may appear to be rare in SaudiArabian and Nigerian children with sickle cell disease, but not in Cameroonian sickle cell patients. Br J Haematol 2006;133:210.

-3 Wonkam A, Njamnshi AK, Angwafo FF 3rd: Knowledge and attitudes concerning medical genetics amongst physicians and medical students in Cameroon (sub-Saharan Africa). Genet Med 2006;8:331-338.

4 Sheth S, Licursi M, Bhatia M: Sickle cell disease: time for a closer look at treatment options? Br J Haematol 2013;162:455-464.
5 Locatelli F, Kabbara N, Ruggeri A, et al: Outcome of patients with hemoglobinopathies given either cord blood or bone marrow transplantation from an HLA-identical sibling. Blood 2013;122:1072-1078.

-6 Wonkam A, Mba CZ, Mbanya D, Ngogang J, Ramesar R, Angwafo FF 3rd: Psychosocial burden of sickle cell disease on parents with an affected child in Cameroon. J Genet Couns 2014;23:192-201.

7 Wonkam A, Njamnshi AK, Mbanya D, Ngogang J, Zameyo C, Angwafo FF 3rd: Acceptability of prenatal diagnosis by a sample of parents of sickle cell anemia patients in Cameroon (sub-Saharan Africa). J Genet Couns 2011;20:476-485.
8 Adeyemi AS, Adekanle DA: Knowledge and attitude of female health workers towards prenatal diagnosis of sickle cell disease. Niger J Med 2007;16:268-270.

-9 Adeola Animasahun B, Nwodo U, Njokanma OF: Prenatal screening for sickle cell anemia: awareness among health professionals and medical students at the Lagos University Teaching Hospital and the concept of prevention by termination. J Pediatr Hematol Oncol 2012;34:252-256.

10 Durosinmi MA, Odebiyi AI, Adediran IA, Akinola NO, Adegorioye DE, Okunade MA: Acceptability of prenatal diagnosis of sickle cell anaemia (SCA) by female patients and parents of SCA patients in Nigeria. Soc Sci Med 1995;41:433-436. 
-11 Brown BJ, Okereke JO, Lagunju IA, Orimadegun AE, Ohaeri JU, Akinyinka OO: Burden of health-care of carers of children with sickle cell disease in Nigeria. Health Soc Care Community 2010;18:289-295.

$\checkmark 12$ Wonkam A, de Vries J, Royal CD, Ramesar R, Angwafo FF 3rd: Would you terminate a pregnancy affected by sickle cell disease? Analysis of views of patients in Cameroon. J Med Ethics 2014;40:615-620.

13 Wonkam A, Mba CZ, Mbanya D, Ngogang J, Ramesar R, Angwafo FF 3rd: Psychosocial stressors of sickle cell disease on adult patients in Cameroon. J Genet Couns 2014;23:948956.

14 Wonkam A, Muna W, Ramesar R, Rotimi $\mathrm{CN}$, Newport MJ: Capacity-building in human genetics for developing countries: initiatives and perspectives in sub-Saharan Africa. Public Health Genomics 2010;13:492-494.

-15 Wonkam A, Tekendo CN, Sama DJ, Zambo H, Dahoun S, Béna F, Morris MA: Initiation of a medical genetics service in sub-Saharan Africa: experience of prenatal diagnosis in Cameroon. Eur J Med Genet 2011;54:e399e404.

-16 Wonkam A, Ngongang Tekendo C, Zambo $\mathrm{H}$, Morris MA: Initiation of prenatal genetic diagnosis of sickle cell anaemia in Cameroon (sub-Saharan Africa). Prenat Diagn 2011;31: 1210-1212.

17 Akinyanju OO, Disu RF, Akinde JA, Adewole TA, Otaigbe AI, Emuveyan EE: Initiation of prenatal diagnosis of sickle-cell disorders in Africa. Prenat Diagn 1999;19:299-304.

18 Wonkam A, Ponde C, Nicholson N, Fieggen K, Ramessar R, Davidson A: The burden of sickle cell disease in Cape Town. S Afr Med J 2012;102:752-754.
19 Wonkam A, Hurst S: A call for policy action in sub-Saharan Africa to rethink diagnostics for pregnancy affected by sickle cell disease: differential views of medical doctors, parents and adult patients predict value conflicts in Cameroon. OMICS 2014;18:472-480.

$20 \mathrm{Xu}$ J, Peng C, Sankaran VG, et al: Correction of sickle cell disease in adult mice by interference with fetal hemoglobin silencing. Science 2011;334:993-996.

21 Wonkam A, Ngo Bitoungui VJ, Vorster AA, et al: Association of variants at $B C L 11 A$ and HBS1L-MYB with hemoglobin F and hospitalization rates among sickle cell patients in Cameroon. PLoS One 2014;9:e92506.

22 Lettre G, Sankaran VG, Bezerra MA, et al: DNA polymorphisms at the BCL11A, HBS1L$M Y B$, and beta-globin loci associated with fetal hemoglobin levels and pain crises in sickle cell disease. Proc Natl Acad Sci USA 2008;105: 11869-11874.

23 Makani J, Menzel S, Nkya S, et al: Genetics of fetal hemoglobin in Tanzanian and British patients with sickle cell anemia. Blood 2011; 117:1390-1392.

24 Mtatiro SN, Makani J, Mmbando B, Thein SL, Menzel S, Cox SE: Genetic variants at HbFmodifier loci moderate anemia and leukocytosis in sickle cell disease in Tanzania. Am J Hematol 2015;90:E1-E4.

$\checkmark 25$ Wonkam A, Rumaney MB, Ngo Bitoungui VJ, Vorster AA, Ramesar R, Ngogang J: Coinheritance of sickle cell anemia and a-thalassemia delays disease onset and could improve survival in Cameroonian patients (sub-Saharan Africa). Am J Hematol 2014;89: 664-665.

26 Rumaney MB, Ngo Bitoungui VJ, Vorster AA, et al: The co-inheritance of alpha-thalassemia and sickle cell anemia is associated with better hematological indices and lower consultations rate in Cameroonian patients and could improve their survival. PLoS One 2014; 9:e100516.
27 Hsu LL, Miller ST, Wright E, et al: Alpha thalassemia is associated with decreased risk of abnormal transcranial Doppler ultrasonography in children with sickle cell anemia. J Pediatr Hematol Oncol 2003;25:622-628.

28 Cox SE, Makani J, Soka D, et al: Haptoglobin, alpha-thalassaemia and glucose-6-phosphate dehydrogenase polymorphisms and risk of abnormal transcranial Doppler among patients with sickle cell anaemia in Tanzania. $\mathrm{Br}$ J Haematol 2014;165:699-706.

29 Flanagan JM, Frohlich DM, Howard TA, et al Genetic predictors for stroke in children with sickle cell anemia. Blood 2011;117:66816684.

30 Ashley-Koch AE, Okocha EC, Garrett ME, et al: MYH9 and APOL1 are both associated with sickle cell disease nephropathy. Br J Haematol 2011;155:386-394.

- 31 Desai AA, Zhou T, Ahmad H, et al: A novel molecular signature for elevated tricuspid regurgitation velocity in sickle cell disease. Am J Respir Crit Care Med 2012;186:359-368.

32 Bean CJ, Boulet SL, Ellingsen D, et al: Heme oxygenase- 1 gene promoter polymorphism is associated with reduced incidence of acute chest syndrome among children with sickle cell disease. Blood 2012;120:3822-3828.

33 Wonkam A, Mayosi BM: Genomic medicine in Africa: promise, problems and prospects. Genome Med 2014;6:11.

-34 Alwan A, Modell B: Recommendations for introducing genetics services in developing countries. Nat Rev Genet 2003;4:61-68.

- 35 H3Africa Consortium: Research capacity. Enabling the genomic revolution in Africa. Science 2014;344:1346-1348. 